JHLSCM

11,2

198

Received 31 July 2020

Revised 30 November 2020 16 January 2021

Accepted 22 January 2021

\section{An analysis of compounding factors of epidemics in complex emergencies: a system dynamics approach}

\author{
Russell Harpring
}

Supply Chain Management and Social Responsibility, Hanken School of Economics, Helsinki, Finland

Amin Maghsoudi

HUMLOG Institute, Hanken School of Economics, Helsinki, Finland

Christian Fikar

Vienna University of Economics and Business, Vienna, Austria and

Supply Chain Management and Social Responsibility, Hanken School of Economics, Helsinki, Finland

Wojciech D. Piotrowicz

HUMLOG Institute, Hanken Svenska Handelshogskolan, Helsinki, Finland, and Graham Heaslip

School of Business, Galway Mayo Institute of Technology, Galway, Ireland and Supply Chain Management and Social Responsibility, Hanken School of Economics, Helsinki, Finland

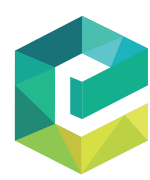

Journal of Humanitarian Logistics and Supply Chain Management Vol. 11 No. 2, 2021 pp. 198-226 Emerald Publishing Limited 2042-6747

DOI 10.1108/JHLSCM-07-2020-0063
(C) Russell Harpring, Amin Maghsoudi, Christian Fikar, Wojciech D. Piotrowicz and Graham Heaslip. Published by Emerald Publishing Limited. This article is published under the Creative Commons Attribution (CC BY 4.0) licence. Anyone may reproduce, distribute, translate and create derivative works of this article (for both commercial and non-commercial purposes), subject to full attribution to the original publication and authors. The full terms of this licence may be seen at http://creativecommons. org/licences/by/4.0/legalcode

This work was supported by the Academy of Finland, under grant decision number 322188, for the project "Cash and/or carry: The challenges and modalities of delivering aid in conflict zones." The authors would also like to express their sincere thanks to Monica Ramos for her generosity and contribution to this research. 
Findings - Compounding factors that influenced the cholera outbreak in Yemen are visualized in a causal loop diagram, which can improve the understanding of relationships where numerous uncertainties exist. A strong link exists between humanitarian response and the level of infrastructure development in a country. Supply chains are affected by constraints deriving from the Yemeni conflict, further inhibiting the use of infrastructure, which limits access to basic goods and services. Aligning long-term development objectives with short-term humanitarian response efforts can create more flexible modes of assistance to prevent and control future outbreaks.

Research limitations/implications - The model focuses on the qualitative aspects of system dynamics to visualize the logistics and supply chain-related constraints that impact cholera prevention, treatment and control through humanitarian interventions. The resulting causal loop diagram is bounded by the Yemen context; thus, an extension of the model adapted for other contexts is recommended for further study.

Practical implications - This study presents a systematic view of dynamic factors existing in complex emergencies that have cause-and-effect relationships. Several models of cholera outbreaks have been used in previous studies, primarily focusing on the modes and mechanisms of transmission throughout a population. However, such models typically do not include other internal and external factors that influence the population and context at the site of an outbreak. This model incorporates those factors from a logistics perspective to address the distribution of in-kind goods and cash and voucher assistance.

Social implications - This study has been aligned with six of the United Nations Sustainable Development Goals (SDGs), using their associated targets in the model as variables that influence the cholera incidence rate. Recognizing that the SDGs are interlinked, as are the dynamic factors in complex humanitarian emergencies, the authors have chosen to take an interdisciplinary approach to consider social, economic and environmental factors that may be impacted by this research.

Originality/value - This paper provides an insight into the underlying inter-relations of internal and external factors present in the context of a cholera outbreak in a complex crisis. Supply chains for food; water, sanitation and hygiene; and health products are crucial to help prevent, control and treat an outbreak. The model exposes vulnerabilities in the supply chain, which may offer guidance for decision makers to improve resilience, reduce disruptions and decrease the severity of cholera outbreaks.

Keywords Humanitarian logistics, Complex emergency, Cash and voucher assistance, Epidemics, In-kind assistance, System dynamics, Resilience, Cholera outbreak, Disruptions, Casual loop diagram

Paper type Research paper

\section{Introduction}

Humanitarian organizations plan for, respond to and assist in recovery from disasters, whether man-made, natural or mix of both. Disasters that occur amid, or as a result of, conflict and political instability often require humanitarian interventions and are classified as "complex emergencies" (UNOCHA, 2018). Such disasters often damage infrastructure and logistics capacities, disrupting services and the flow of basic commodities (Puri et al., 2017). Disruptions in one segment of the supply chain can impact all other echelons for a prolonged period (Ivanov et al., 2014). The unpredictability of events in complex emergencies leaves humanitarian supply chains ( $\mathrm{HSCs}$ ) vulnerable to disruptions and may reduce the effectiveness of responses by aid agencies, which rely on external resources and a network of actors, including donors, suppliers, non-governmental organizations (NGOs), service providers and governmental agencies (Kovács and Tatham, 2009). Consequently, vulnerable populations affected by complex emergencies may be exposed to greater risks due to access and availability constraints for attaining basic goods and services.

One of the major risks of mortality in complex emergencies is that of communicable diseases, especially diarrheal diseases that have the capability of spreading rapidly once control mechanisms are restricted or removed (Connolly, 2005). Cholera is one of the major diseases that poses a serious risk to populations in complex emergencies. The primary mode of transmission is through contaminated water sources, meaning that populations that lack of access to safe water and sanitary facilities are most vulnerable. Victims experience a rapid onset of acute watery diarrhea, which may cause severe dehydration or death in a matter of hours (WHO, 2009). Conflict and other events that displace populations contribute to the likelihood of an outbreak, as the movement and temporary settlement of persons increases
Compounding factors of epidemics 
JHLSCM 11,2

the risk of transmission (Chaignat and Monti, 2007). As Kelly-Hope (2008) note, primary risk factors for cholera coincide with the consequences of conflict: poverty, displacement, lack of access to facilities and lack of safe drinking water. In a review of a study on emerging diseases in conflicts (Gayer et al., 2007), cholera outbreaks were reported in nearly every conflict zone from 1990 to 2006 alongside other infectious diseases (Kelley-Hope, 2008).

The Global Task Force on Cholera Control (GTFCC) acknowledges that cholera is a preventable disease, but one in which outbreaks persist and remain prevalent, especially in fragile and conflict-affected areas (GTFCC, 2017). The GTFCC cites the cholera outbreak in Yemen as one of the worst in modern times, with over 2.3 million suspected cases since 2016. The situation has been made worse by the ongoing conflict, failing infrastructure and food insecurity that the country faces. To prevent outbreaks such as this from occurring in the future, the GTFCC has created a roadmap to eliminate the threat of cholera by 2030 and aims to reduce cholera mortality by $90 \%$ in the same timeframe. Basic needs such as food; health care; and water, sanitation and hygiene products (WASH) are critical to reduce the incidence rate of cholera and control the spread of infection during an outbreak. The provision of these supplies relies on a coordinated logistical effort from multiple actors. Thus, it is important to understand the underlying structure and relationships in HSCs that provide those goods and services for the protection of populations.

Consequently, decision-making in rapidly changing environments requires a thorough understanding of the problem (Kapucu and Garayev, 2011), with special attention paid to key stakeholders and contextual factors, which may change rapidly (Dinizet et al., 2005). Adopting a systems perspective of the problem context is useful for analyzing interactions of entities within a system and learning how a system behaves (Sterman, 2000). In this manner, mapping interrelationships of key stakeholders along HSCs can reveal logistics barriers and potential improvements through systems analysis (Heaslip et al., 2012). With this in mind, a system dynamics (SD) methodology is suggested in this work. Besiou et al. (2011) note that SD models can assist humanitarian decision makers to explore possible courses of action in highly uncertain environments. The focus of this work is set on the qualitative aspects of SD, i.e. causal loop diagrams (CLDs), to visualize the numerous factors that directly and indirectly affect humanitarian responses during a cholera outbreak occurring in a specific context. Using CLDs without quantification does have drawbacks, as behavior is not deduced, but only inferred, making the magnitude of feedback effects difficult to represent (Lane, 2008). However, when used correctly, qualitative models can provide value by depicting complex systems in a manner that can improve understanding of relationships where numerous uncertainties exist (Coyle, 2000). This research uses the strengths of qualitative SD approaches to promote systems thinking and provide visualization of feedback loops for decision makers (Wolstenholme, 1999). Thus, the research objectives (RO) of this paper are as follows:

RO1. To identify key internal and external factors that either aggravate or mitigate the risk of a cholera outbreak in a complex emergency.

RO2. To develop a visualization of the causal relationships and dynamic effects of the identified variables from RO1 using the SD methodology.

RO3. To explore the connection between relevant sustainable development goals and responding to needs to improve preparedness measures toward future epidemics.

This research has been aligned with six of the United Nation's (UN's) Sustainable Development Goals (SDGs), using their associated targets in the model as variables that influence the cholera incidence rate. Recognizing that the SDGs are interlinked, as are the dynamic factors in complex humanitarian emergencies, we have chosen to take an interdisciplinary approach to consider social, economic and environmental factors that may 
be impacted by this research. Thus, in aiming to achieve the primary objectives of this work as stated above, the following SDGs may be positively impacted: (SDG 1) no poverty; (SDG 3) good health and well-being; (SDG 4) quality education; (SDG 6) clean water and sanitation; (SDG 9) industry, innovation and infrastructure; and (SDG 11) sustainable cities and communities.

The remainder of this paper is structured as follows. The next section describes the applications of SD methods in both humanitarian operations and epidemic modeling. Section 3 outlines the framework for the model, including an analysis of the context used for the model. Section 4 discusses the key factors and causal relationships from the model, implications for humanitarian decision makers and limitations to the model. Finally, Section 5 provides a conclusion and suggests areas for future research.

\section{Preparing for epidemics in complex emergencies}

Several definitions exist for "complex emergencies," including the characteristics that define such situations. Most are derived from the UN Office for the Coordination of Humanitarian Affairs (UNOCHA) definition, which states it as "a humanitarian crisis in a country, region or society where there is total or considerable breakdown of authority resulting from internal or external conflict and which requires an international response that goes beyond the mandate or capacity of any single agency and/or the ongoing United Nations country program" (IASC, 1994). Other scholars have expanded upon this definition to include additional characteristics and attributes. Burkle (1999) summarized these characteristics and provided a simplified definition as, "the international response to state disruption and its sustaining infrastructure." Despite the varying definitions, Macias (2013) notes that while definitions may differ, the root causes of complex emergencies do not. In a critical literature review on studies of "complex emergencies," the following characteristics were present across all complex emergencies: (1) conflict or political instability, (2) environmental effects, (3) poverty or vulnerability of an affected population and (4) social and economic factors.

These characteristics have been found to be drivers of epidemics during complex emergencies, often through a series of cascading factors (Hammer et al., 2018). For example, armed conflict may force population displacement and limit access to health services, leading to a need for humanitarian assistance and international aid, which may be hindered by disrupted logistics activities, exacerbating the risk of the spread of communicable diseases. The World Health Organization (WHO) recognizes that communicable diseases are a major cause of mortality in complex emergencies (Connolly, 2005), especially when basic needs are no longer met. Preventing and controlling communicable diseases in such environments require safe water, food, sanitary facilities, shelter, good hygiene practices and health care. The provision of these commodities and services in emergencies, when local supply chain fails, relies on HSCs. Unfortunately, transportation networks are vulnerable in disaster settings, leading to disruptions in the supply of relief items (Berariu et al., 2015).

Resilience in HSCs can lessen the impact of disruptions by reducing exposure to risks (Peck, 2006) and having sufficient capacity to recover and return to the original state, or greater (Jüttner and Maklan, 2011). Papadopoulos et al. (2017) argue that supply chain resilience is dependent upon the quality of infrastructure at the time of the disaster. Infrastructure relies upon economic and social development; thus, least-developed countries (LDC) are generally less resilient to disasters and are hindered by structural constraints, making supply disruptions more severe. Decision makers in complex humanitarian emergencies must consider flexible modes of support to continuously meet needs in a dynamic environment (Piotrowicz, 2018). In this manner, implementing both proactive and reactive response measures can reduce risk of severe disruptions (Elluru et al., 2017).

In-kind assistance and cash and voucher assistance (CVA) are two complementary modalities that can be used to meet needs across multiple sectors (Sabates-Wheeler and 
JHLSCM

11,2

Devereux, 2010). Devereux (2006) strongly argues that CVA and in-kind assistance have become unnecessarily polarized. Instead of being pitted against one another, the context and environmental situations should guide response efforts as cash can be delivered in some circumstances, and commodities, using the in-kind modality, in others. CVA provides financial support directly to beneficiaries, giving them a flexible means to cover their needs. For humanitarian organizations, this can reduce the dependence on transportation, warehousing and delivery of goods, ultimately lowering logistics costs and enabling beneficiaries to meet their needs quicker and more accurately (Heaslip et al., 2018). However, there are several prerequisites to CVA implementation, including the presence of functioning markets that are accessible for beneficiaries and offer sufficient quantities of needed goods or services (ECHO, 2013). The provision of CVA as a standalone mode of support may not be enough to mitigate the risk of supply disruptions, but providing it alongside other forms of support gives decision makers the option to respond according to the current circumstances and adjust their strategy accordingly (Piotrowicz, 2018). Market-based programming is a flexible sourcing strategy that is guided by market analyses to determine which mode of response, or combination thereof, would be most efficient and cost-effective in a given context (Martin-Simpson et al., 2018). As this type of approach takes advantage of both the private and humanitarian sector to meet the needs of a population, there is a greater capacity to provide an effective response, potentially lessening the effects of supply disruptions.

Regardless of how a response is formulated, decision makers should be aware of both intended and potentially unintended consequences of a chosen strategy. Unintended consequences are not always obvious, as causal relationships can be distantly linked over time and space (Sterman, 2000). Given the number of dynamic factors in complex emergencies, actions can create ripple effects, leading to direct and indirect outcomes along a chain (Ivanov et al., 2014). For this reason, several studies in humanitarian operations have suggested adopting a systems perspective to approach multi-faceted problems and be better prepared for such potential outcomes. SD has been used in the humanitarian sector before to explore complex causal relationships in food distribution supply chains (Armendàriz et al., 2016), performance management in humanitarian organizations (Anjomshoae et al., 2017), humanitarian relief and recovery operations (Gonçalves, 2011) and for the logistics of field vehicle fleet management in the humanitarian context (Besiou et al., 2011).

An SD approach can equip decision makers in humanitarian settings with tools to better predict longitudinal consequences of actions taken in a defined context (Besiou et al., 2011) and can be used as a training tool to improve responses to disasters through simulated scenarios (Berariu et al., 2016). Sterman (2000) notes that the SD methodology is designed for use in non-linear systems of dynamic complexity, where interactions among actors create feedback loops with time-dependent effects. The causal (cause and effect) relationships can be visualized through CLDs, which are important for understanding how actors are connected in a network and how their actions lead to certain effects. Links in the system are one-directional and can be positive or negative, depending on the type of effect the action creates. As more links are established, loops will form, which can be reinforcing or balancing, representing positive or negative feedback, respectively (Sterman, 2000). CLDs that mimic real-world systems help explain behavior in the system and allow visualization of the entire system as a whole and as individual parts with underlying feedback mechanisms, which can be a powerful tool for making decisions against complex settings.

\subsection{Systems dynamics in epidemic modeling}

Epidemiology studies have utilized SD tools and models to understand how communicable diseases spread throughout a population over time. One of the most used frameworks is the susceptible-infectious-recovered (SIR) model, in which individuals in a system are susceptible to being infected and ultimately recover or are removed from the system (Anderson and May, 1991). SIR models have been used in humanitarian contexts to study the 
dynamics of transmission and recovery rates for diseases such as cholera (Mukandavire and Morris, 2015), HIV (Perelson, 2002), Ebola (Rachah and Torres, 2015), influenza (Pruyt and Hamarat, 2010) and COVID-19 (Wu et al., 2020).

In a review of studies that incorporate models that depict cholera outbreaks and interventions, the majority seek to understand the modes of transmission, pathogen movement and effectiveness of interventions (Chao et al., 2014). These models often cite environmental and exogenous factors that influence the velocity of disease spreading and severity of an epidemic. For instance, as a waterborne disease, the spread of cholera is attributed to environmental factors, including flooding and droughts, which may contaminate water supplies or drive populations to drink unsafe water (Codeco, 2001). As the disease has the potential to spread rapidly throughout a population, the WHO states that even a single confirmed case of cholera is sufficient to declare an outbreak and initiate response measures (Connolly, 2005).

Common interventions to counter an outbreak of cholera include the provision of WASH products and oral cholera vaccinations (OCVs) to stop the spread of the disease. Both CVA and in-kind assistance may be used to cover the needs. However, an optimal intervention in one context might not be the most effective in another context. Grad et al. (2012) urge caution when quantifying and reporting the effectiveness of cholera interventions, noting that context-specific parameters influence model behavior and output. As such, modeling of interventions should consider demographic, geographic and time-sensitive data when making claims toward effectiveness of an intervention. This is especially important for interventions in complex emergencies, which involve cascades of risk factors with multiple feedback loops (Hammer et al., 2018). Interventions in contexts that are not fully scoped out may result in unintended consequences.

Regardless of the intervention chosen, logistics operations and capacities are required for the provision and delivery of needed commodities. However, logistics is not always able to provide goods in complex emergencies. Numerous gaps in research pertaining to the logistics of responses for controlling epidemics remain, including multidisciplinary and holistic approaches (Dasaklis et al., 2012). Diarrheal diseases remain one of the main causes of morbidity and mortality in emergencies (Connolly, 2005), and delays in the provision of relief can lead to a loss of life. This prompts the necessity of resilient supply chains to provide effective interventions when and where they are needed. To do so, an understanding of the whole system is required. Thus, the motivation of this research is to expand upon existing SD models for cholera outbreaks by including logistics and supply-related challenges of humanitarian organizations operating in complex emergencies. The following section explains the methods for building the CLD and an overview of the Yemeni context.

\section{Methodology and model basis}

The development of the CLD followed guidelines provided by Sterman (2000) and involved an iterative process of reviewing relevant literature to establish causal links, attributing polarity to each link, identifying balancing and reinforcing loops in the model and revising the boundaries of the model as more information emerged. Relevant literature consisted of publications and reports from UN agencies, governments and NGOs that describe operations to prevent, control and treat outbreaks of cholera in Yemen. In addition, a series of interviews with a senior executive of the GTFCC was conducted for model validity. The interviewee had more than ten years of experience working with UN agencies against outbreaks in complex emergencies and had first-hand experience with cholera control in Yemen during the height of the outbreak in 2017.

\subsection{Inductive review of literature}

The review of literature began with empirical data related to the spread of cholera in Yemen, then expanded to understand the causal and cascading factors that led to an epidemic.
Compounding factors of epidemics 
JHLSCM 11,2

Investigation began with the mechanics of cholera propagation to identify causal relationships with elements present in the Yemen context. For instance, it is well established that cholera is a waterborne disease, but less is known about how sources of water become contaminated and why Yemenis do not have access to safe water. Therefore, we inductively looked for causal patterns in the literature to capture the Yemen context and compounding factors that influence the spread of cholera.

\section{4}

\subsection{Yemen context}

According to the UN, the humanitarian crisis in Yemen is the worst in the world (UNOCHA, 2019). The ongoing conflict has been oscillating in intensity since 2014, as the internationally recognized government (IRG) and coalition forces fight for control against the de facto authorities (DFA) in the northeast. The situation has grown into a protracted crisis with more than 24 million people in need of assistance in-country (REACH, 2019). Yemen has long been vulnerable to poverty and instability, ranking only 177th out of 189 countries in the UNDP's 2019 Human Development Index (Conceição, 2019). Furthermore, ACAPS (2019) lists the crisis severity in Yemen as "Very High Severity," a critical designation shared with only five other countries globally. The population in Yemen grew from 7.95 million in 1980 to 29.17 million in 2019 (World Bank, 2020b). Despite increased local food production, Yemen relies heavily on imports, with $90 \%$ of food sources arriving from other countries (UNOCHA, 2018).

The Logistics Cluster conducts capacity assessments to evaluate infrastructure (e.g. port/ airport, road/rail, storage capacity and local transportation resources) and services (e.g. financial, education, health, insurance and customs) in countries and regions of operation. In the assessment of Yemen, the Logistics Cluster noted the infrastructure lacked development before the start of the conflict and has since sustained extensive damage from both the DFA and IRG (Logistics Cluster, 2010). UNOCHA's Humanitarian Needs Overview (2019) reports that the destruction of public and civilian infrastructures has caused access constraints, limiting the use of roads, stalling seaport activities, and more importantly, collapsing half of the public health facilities.

Against these settings, Yemenis were subjected to one of the largest cholera outbreaks in epidemiologically recorded history, with over 2.3 million reported cases from October 2016 to January 2020 (WHO, 2020). The lack of available and accessible health services, medicines and safe water worsened the situation, as goods needed to be transported through seaports, which were damaged in the conflict. As a result, the importing of basic commodities was reduced, reflecting a lack of confidence from suppliers and shipping companies due to heavy restrictions and poor maritime infrastructure. As the seaports are key supply routes for other commodities besides humanitarian aid, they have been targeted by both factions of the conflict, resulting in supply disruptions to most of the country. For example, in November 2017, a blockade of the port by the IRG and coalition forces resulted in a halt of the flow of supplies into the northwest of the country, spoiling tons of food and medical supplies at sea (Fink, 2017). This further exacerbated the cholera outbreak, as displaced populations resorted to negative coping mechanisms, such as reduced clean water purchases and lower food consumption, which further spread the disease (Federspiel and Ali, 2018; UNOCHA, 2019). Disruptions not only affect beneficiaries, but may distort markets and supply lines, reducing the purchasing power of both market suppliers and beneficiaries. Thus, the inadequate infrastructure amid the ongoing conflict had a compounding effect and hampered efforts to prevent and control the cholera outbreak in 2017.

\subsection{Influential external factors in Yemen}

In the CLD, external factors represent uncontrollable forces that affect the model's internal variables. These variables have no inputs inside the boundaries of the model, therefore only exert influence through outputs to create second order effects. In the review of literature, five 
key external factors were identified, which had a high degree of influence in the situation in Yemen:

(1) Ongoing conflict between DFA in the north and IRG separatists in the south has created an invisible border in Yemen, leading to population displacement, supply network disruptions and severe damage to civilian and economic infrastructure.

(2) Lack of infrastructure development refers to the state of infrastructure development before the start of the conflict, including an outdated water network, poor road conditions, limited telecommunications network and vulnerable power grid. This state of vulnerability reduced the ability to recover from damage sustained during the conflict.

(3) Extreme weather events include droughts, heavy rainfall, floods, cyclones and climate change-related disasters. These have negative impacts on existing infrastructure by damaging transportation systems, agriculture, water supply and the energy sector.

(4) Cultural and social factors such as the high population density in urban environments; frequent use of remittances; societal hierarchies, including the status of women, children and other at-risk groups. This influences hygienic knowledge and customs, ranging from personal hygiene habits to burial practices, which may pose a risk to public health.

(5) Market functionality refers to the stability of national, regional and local markets that the population relies upon for basic goods and services. Market functionality is necessary for CVA and must be assessed before and intervention takes place.

The effects created by these external variables are presented in the following subsection, which provides the basis of the model through the identification of causal relationships.

\subsection{Consequences of compounding factors}

Individual risk factors in complex emergencies interact with and exacerbate other factors, which can cause both cascading effects and feedback loops (Hammer et al., 2018). Tables 1-5 summarize the ways in which the external factors affect the system by highlighting important causal relationships derived from reports and literature. Several of the factors are overlapping with one another, due to the fact that the majority of variables have multiple inputs and outputs.

Table 1 presents the effects of the ongoing conflict between the DFA in the north and IRG in the south. The continuous fighting has damaged the social, physical and economic infrastructure in Yemen. Basic health and education services quickly became inaccessible or inoperable in embattled areas. Food and water shortages became common as a result of the damaged water and supply networks. The World Food Programme (WFP) notes that the country is extremely fragile due to the reliance on imported food and volatile local currency (Caccavale et al., 2018). Despite the desperate need for functioning seaports in Al-Hudaydah and Aden, both have been damaged since the start of the conflict and are operating at reduced capacity (ACAPS, 2019). As infrastructure deteriorates, so does the transportation systems that carry commodities and valuable exports. The economic collapse and insecurity drives mass internal displacement, leading to overcrowding in urban environments, and further reduces the availability of goods in those areas.

Before the start of the conflict, the infrastructure in Yemen was already in inadequate condition with limited energy supply from state-owned power plants, neglected roads primarily built in the 1970s and 1980s and inefficient water extraction methods that quickly drained the country's primary aquifers (Medicini, 2014). The economic downturn in 2008, Arab Spring in 2011 and subsequent events that led to the start of the civil war in 2015

Compounding factors of epidemics 
JHLSCM 11,2

\section{6}

Table 1.

Main compounding factors related to the ongoing conflict
Second-order

effects

Causal relationships

References

Damage to

infrastructure

Lack of basic services

(1) Damage to infrastructure, such as AlHudaydah port, caused supply chain disruptions affecting public and private services

(2) Disruption of power supply and water network, causing water contamination and

Economic collapse accumulation of solid and human waste

Lack of basic commodities

Diminished local currency and purchasing power

(1) An estimated 50\% economic contraction since 2015

(2) $81 \%$ of Yemenis living below poverty line

(3) Low beneficiary purchasing power reduced demand for goods

(4) Reduced beneficiary purchasing power reduced supplier purchasing power

(5) Price inflation, coupled with reduced purchasing power, increased needs of food, water, medicine and shelter

Lack of basic commodities

Price inflation

(1) Inflated transportation and production costs

(2) Cost of food basket increased by $94 \%$ since 2015

(3) Wholesalers withhold supplies due to highly volatile exchange rates and lack of foreign currency, retailers may not able to restock regularly, adding up the prices

(4) Affects usability and feasibility of CVA programs

Lack of basic services

Increased unemployment rate:

(1) Employment and income opportunities diminished since 2016

(2) More than 600,000 jobs estimated to have been lost mainly in agriculture and service sector

(3) Health-care workers without pay for more than 10 months, with many leaving their positions

Population displacement

Overcrowding

(1) Displacement may reduce the amount of clean water available per person

(2) 3.6 million internally displaced persons due to the conflict
ACAPS (2019), Chaignat and Monti (2007), Federspiel and Ali (2018)

ACAPS (2020a), Caccavale et al. (2018), Federspiel and Ali (2018), WHO (2017)

ACAPS (2020a), Caccavale et al. (2018), Cash Learning Partnership (CaLP) (2018), FAO et al. (2018)

Caccavale et al. (2018), WHO (2017)

Caccavale et al. (2018), Chao et al. (2014), UNHCR (2020) 


\begin{tabular}{ll}
$\begin{array}{l}\text { Second-order } \\
\text { effects }\end{array}$ & Causal relationships \\
\hline $\begin{array}{l}\text { Power cuts and fuel } \\
\text { shortages }\end{array}$ & Lack of basic services and commodities \\
(1) $\begin{array}{l}\text { Fuel shortages reduce the possibility of water } \\
\text { trucking, while the major cost of water } \\
\text { trucking is the price of fuel }\end{array}$ & (2) $\begin{array}{l}\text { Most fuel is imported through Al-Hudaydah } \\
\text { and Aden ports, while the ports were blocked } \\
\text { due to the conflict and road to the main cities } \\
\text { were damaged }\end{array}$ \\
& (3) $\begin{array}{l}\text { Electricity and water network cuts shut } \\
\text { down some of the health and education } \\
\text { facilities }\end{array}$ \\
(4) $\begin{array}{l}\text { Fuel scarcity contributed to low level of } \\
\text { imports, currency crisis and poor supply of } \\
\text { goods into local markets }\end{array}$
\end{tabular}

References

ACAPS (2019), Caccavale et al. (2018)

\section{Compounding factors of epidemics}

\begin{tabular}{ll}
$\begin{array}{l}\text { Second-order } \\
\text { effects }\end{array}$ & Causal relationships \\
\hline $\begin{array}{l}\text { Inadequate water } \\
\text { supply }\end{array}$ & Lack of basic services and commodities \\
& (1) $\begin{array}{l}\text { Lack of clean water drives people, who are often } \\
\text { displaced, to find alternative water sources that } \\
\text { may be contaminated }\end{array}$ \\
& (2) $\begin{array}{l}\text { Delivery of water trucking by humanitarian } \\
\text { organizations can provide clean and safe water } \\
\text { to affected population. However, the lack of road } \\
\text { infrastructure and lack of fuel has made it } \\
\text { difficult for water trucking delivery }\end{array}$ \\
& (3) $\begin{array}{l}\text { Lower import levels reflect a lack of shipping } \\
\text { confidence due to heavy restrictions and poor } \\
\text { port infrastructure }\end{array}$ \\
$\begin{array}{l}\text { Power cuts and } \\
\text { fuel shortages }\end{array}$ & (1) $\begin{array}{l}\text { Inadequate infrastructure limits how waste is } \\
\text { disposed of, leading to improper waste } \\
\text { management practices }\end{array}$ \\
& (2) $\begin{array}{l}\text { Failure to deliver OCVs until 16 months after } \\
\text { cholera outbreak }\end{array}$ \\
& (3) $\begin{array}{l}\text { Only } 45 \% \text { of health facilities operational since } \\
\text { beginning of conflict in } 2015\end{array}$
\end{tabular}

References

Caccavale et al. (2018), Chao et al. (2014), Federspiel and Ali (2018)

Federspiel and Ali (2018), Fuss (2016), WHO (2017)

Table 2. Main compounding factors related to the lack of infrastructure development

hindered efforts to further develop Yemen's infrastructure. Since the start of the conflict, extensive damage has been caused to the key networks, crippling logistic activities and hindering humanitarian efforts. The Al-Hudaydah seaport suffered from airstrikes and a blockade while a key bridge to Sana'a, where roughly $80 \%$ of the country's food traders are located, was knocked out due to the fighting. Hospitals, schools and other civilian infrastructure also suffered heavy damage.

If, according to Papadopoulos et al. (2017), supply chain resilience is directly affected by the quality of infrastructure prior to a disaster, then Yemen's remaining logistic constraints 


\section{JHLSCM 11,2}

Table 3.

Main compounding factors related to extreme weather events

\begin{tabular}{|c|c|c|}
\hline $\begin{array}{l}\text { Second-order } \\
\text { effects }\end{array}$ & Causal relationships & References \\
\hline \multirow{4}{*}{$\begin{array}{l}\text { Hygienic } \\
\text { practices }\end{array}$} & Lack of basic commodities & \multirow{4}{*}{$\begin{array}{l}\text { WHO (2010), } \\
\text { WHO (2004) }\end{array}$} \\
\hline & $\begin{array}{l}\text { (1) Inadequate hygienic practices may be a result of educational } \\
\text { awareness and lack of means of sanitary supplies, such as } \\
\text { soap, chlorine and safe water } \\
\text { Lack of basic services }\end{array}$ & \\
\hline & (1) Need awareness regarding proper burial practices for & \\
\hline & $\begin{array}{l}\text { (2) Personal hygiene facilities not sanitized or non-existent in } \\
\text { many locations }\end{array}$ & \\
\hline \multirow[t]{5}{*}{ Overcrowding } & Reliance on informal networks & \multirow[t]{5}{*}{ WHO (2004) } \\
\hline & $\begin{array}{l}\text { (1) Large gatherings may occur in markets, queueing for } \\
\text { distribution of relief goods or to access services }\end{array}$ & \\
\hline & $\begin{array}{l}\text { (2) Community involvement is needed to spread proper health- } \\
\text { related information }\end{array}$ & \\
\hline & Lack of basic commodities & \\
\hline & $\begin{array}{l}\text { (1) Urban overcrowding, combined with food and water } \\
\text { shortages, increases the chance of traveling to access basic } \\
\text { needs, often into crowded environments }\end{array}$ & \\
\hline
\end{tabular}

\section{Table 4.}

Main compounding factors related to cultural and social factors

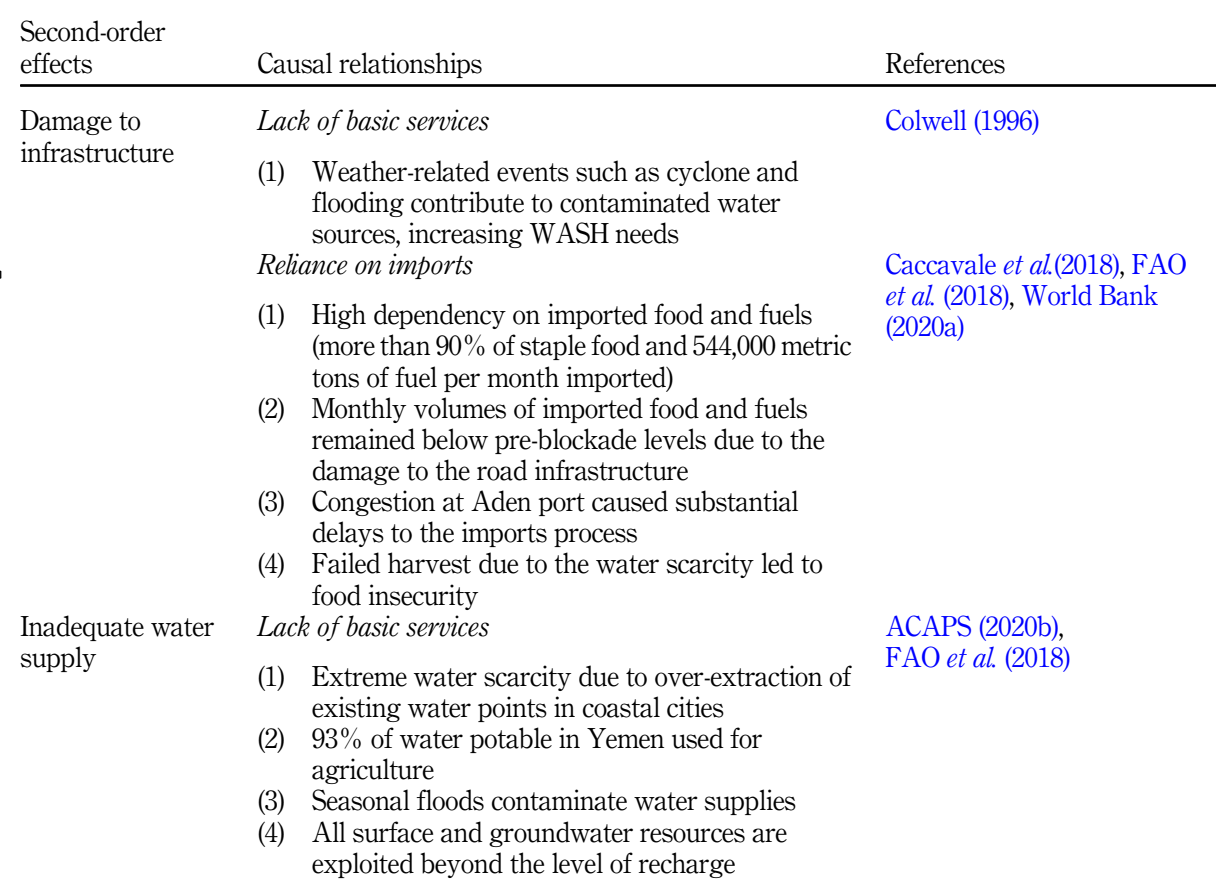

\begin{tabular}{|c|c|c|}
\hline $\begin{array}{l}\text { Second-order } \\
\text { effects }\end{array}$ & Causal relationships & References \\
\hline \multirow{7}{*}{$\begin{array}{l}\text { Damage to } \\
\text { infrastructure }\end{array}$} & Lack of basic services & Colwell (1996) \\
\hline & $\begin{array}{l}\text { (1) Weather-related events such as cyclone and } \\
\text { flooding contribute to contaminated water } \\
\text { sources, increasing WASH needs }\end{array}$ & \\
\hline & Reliance on imports & \multirow{5}{*}{$\begin{array}{l}\text { Caccavale } \text { et al.(2018), FAO } \\
\text { et al. (2018), World Bank } \\
\text { (2020a) }\end{array}$} \\
\hline & $\begin{array}{l}\text { (1) High dependency on imported food and fuels } \\
\text { (more than } 90 \% \text { of staple food and } 544,000 \text { metric } \\
\text { tons of fuel per month imported) }\end{array}$ & \\
\hline & $\begin{array}{l}\text { (2) Monthly volumes of imported food and fuels } \\
\text { remained below pre-blockade levels due to the } \\
\text { damage to the road infrastructure }\end{array}$ & \\
\hline & $\begin{array}{l}\text { (3) Congestion at Aden port caused substantial } \\
\text { delays to the imports process }\end{array}$ & \\
\hline & $\begin{array}{l}\text { (4) Failed harvest due to the water scarcity led to } \\
\text { food insecurity }\end{array}$ & \\
\hline \multirow{5}{*}{$\begin{array}{l}\text { Inadequate water } \\
\text { supply }\end{array}$} & Lack of basic services & \multirow{5}{*}{$\begin{array}{l}\text { ACAPS (2020b), } \\
\text { FAO et al. (2018) }\end{array}$} \\
\hline & (1) Extreme water scarcity due to over-extraction of & \\
\hline & $\begin{array}{l}\text { (2) } 93 \% \text { of water potable in Yemen used for } \\
\text { agriculture }\end{array}$ & \\
\hline & (3) Seasonal floods contaminate water supplies & \\
\hline & $\begin{array}{l}\text { (4) All surface and groundwater resources are } \\
\text { exploited beyond the level of recharge }\end{array}$ & \\
\hline
\end{tabular}
et al. (2018), World Bank (2020a)

existing water points in coastal cities

3) Seasonal floods contaminate water supplies exploited beyond the level of recharge

\section{Colwell (1996)}

\section{8}




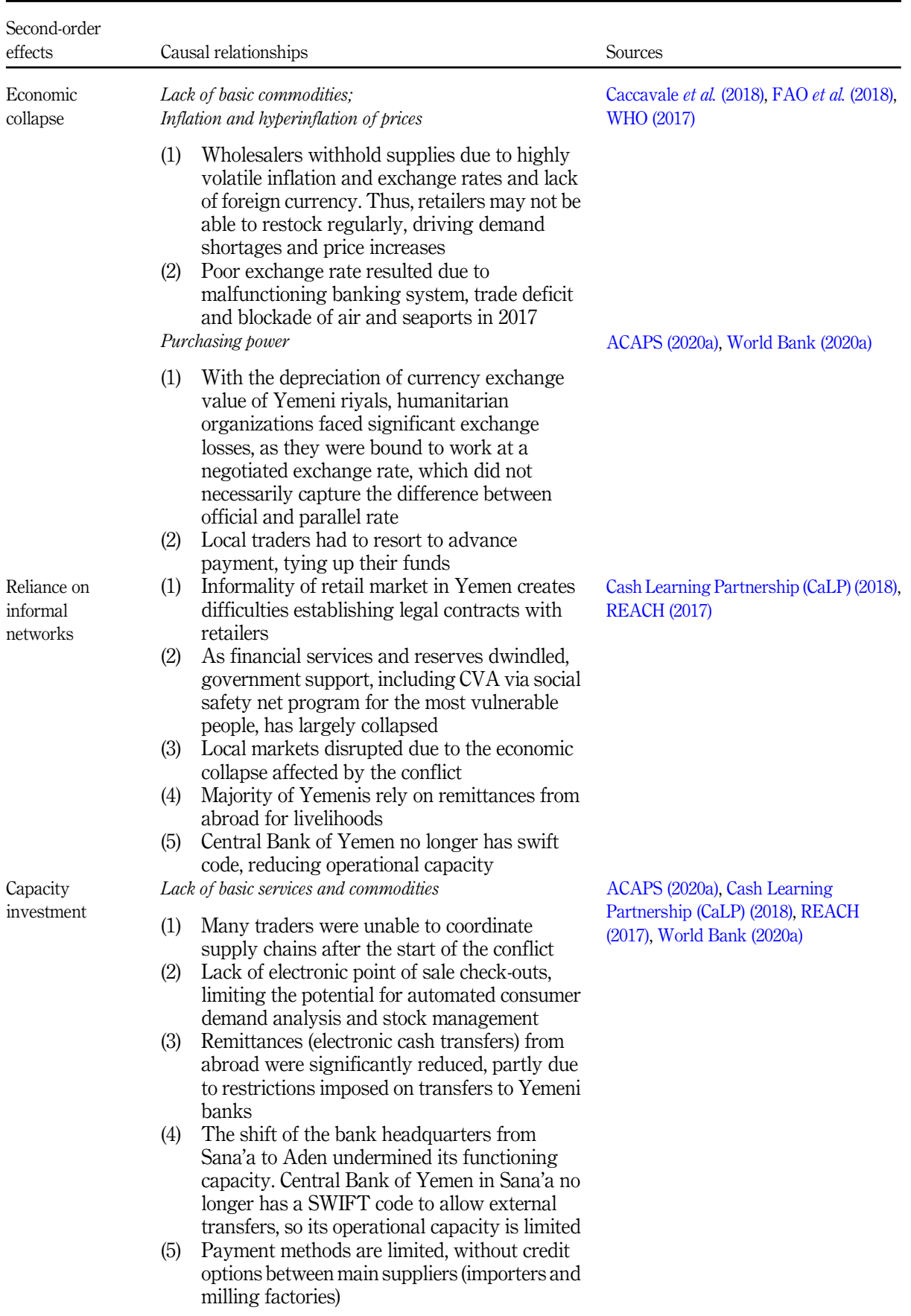

\section{Compounding factors of epidemics}
Economic Lack of basic commodities,
(1) Wholesalers withhold supplies due to highly volatile inflation and exchange rates and lack of foreign currency. Thus, retailers may not be able to restock regularly, driving demand exce increases malfunctioning banking system, trade deficit and blockade of air and seaports in 2017

(1) With the depreciation of currency exchange value of Yemeni riyals, humanitarian organizations faced significant exchange necessarily capture the difference between

payment, tying up their funds informal networks

\section{Capacity} investment limiting the potential for automated consumer demand analysis and stock management abroad were significantly reduced, partly due to restrictions imposed on transfers to Yemeni capacity. Central Bank of Yemen in Sana'a no longer has a SWIFT code to allow external transfers, so its operational capacity is limited milling factories)
Table 5.

Main compounding factors related to market functionality 
JHLSCM 11,2 after the conflict must also be attributed to the lack of initial development. Table 2 demonstrates how, even with international humanitarian organizations present in the country, the distribution of supplies can still be disrupted due to reduced port capacity, restricted road access and a limited number of water pumping sites, creating a situation vulnerable to epidemics. Controlling an outbreak of cholera requires immediate action and rapid treatment (Connolly, 2005). Medical supplies and personnel are needed for effective containment, often relying on stockpiles and pre-positioned inventories (Dasaklis et al., 2012). Delays in the response effort, due to disruptions in the supply chain or constraints in logistic capacities, can severely hinder efforts for containment. For this, we have attributed only one delay in the model to denote the importance of how a delay of in-kind aid affects the availability of basic commodities to people in need.

Environmental causes related to the spread of cholera are well documented in literature, owing to the fact that the primary mode of transmission is through water sources. As noted in Table 3, extreme weather events, including global climate change, can lead to flooding, droughts and cyclones in Yemen, which has ripple effects in the consumption patterns in the population. The efficient use of clean water and sustainable methods of extracting groundwater is crucial for the development of Yemen moving forward. While extreme weather events are uncontrollable, the ability to recover from them is attributed to resilience and infrastructural development.

Factors stemming from cultural and social norms (Table 4) are not as easy to remedy but must be addressed with respect to their implications for the spread of cholera. Involvement of local community leaders is important to help identify vulnerable groups, understand culturally sensitive customs and disseminate health-related knowledge (WHO, 2004). In Yemen, the lack of education can undermine efforts to control cholera by lack of awareness of hygienic practices. For this, OCV campaigns have two purposes: to administer vaccinations and to disseminate information for cholera awareness. The GTFCC (2017) notes that safe food preparation, adequate hand-washing techniques and proper burial practices must be observed to reduce the risk of transmitting cholera to healthy individuals.

Table 5 summarizes how markets affect the purchasing power of beneficiaries and suppliers, along with banking regulations and the dependence upon remittances in the country. This model labels market functionality as an external variable that is not affected by other variables in the model. As the study of influential factors on markets is complex enough, the purpose the variable serves for this model is to primarily show how in-kind assistance and CVA are affected by the existence of functioning markets. Given the logistic constraints in Yemen, CVA is a cost-effective solution that can complement in-kind assistance. Cash transfers for WASH products can create a large impact for targeted communities, but rely on markets and financial service providers for successful implementation. If markets do not function, then the provision of CVA does not provide value to beneficiaries. Thus, a marketbased solution is encouraged that utilizes both CVA and in-kind assistance to provide flexible aid to beneficiaries, potentially increasing resiliency if one form cannot be utilized.

The relationships discussed in the tables form the basis for the construction of the CLD. The following subsection presents the CLD in three parts: the cholera outbreak, the response and the context. Each component of the model is examined both individually and in relation to the other parts.

\subsection{Causal loop diagram (CLD)}

CLDs represent the qualitative part of an SD by focusing on relevant causes and effects in the considered system. A CLD consists of variables, which are linked by arrows. Each arrow is indicated by either a plus (+) or minus (-) sign. A positive link, i.e. one denoted by a plus sign, indicates that an increase in the cause leads to an increase in the effect, while a negative sign means that if the cause increases, the effect decreases. Additionally, delays can be modeled to 
specify that a certain effect occurs at a later point in time. Such delays are indicated by double lines $(||)$ that cross the link in our representation. By visualizing these relationships between the considered variables, feedback loops in the system can be identified. Such loops can either have a balancing $(B)$ or reinforcing $(R)$ effect on the system to highlight how the variables interrelate. For a detailed description of CLDs, refer to Morecraft (2007).

The CLD designed in this study has three core components: (1) an SIR module depicting the transmission of cholera throughout a population, (2) a module that represents the humanitarian efforts to provide relief and (3) a module containing the compounding internal and external factors that influence component (2) and subsequently (1). The final version of the model is not comprehensive, nor should it be, according to Sterman (2000). Rather, the purpose of the model is to provide a structural view of the humanitarian response to a cholera outbreak to gain insight into the existing feedback loops that govern the system.

The model is presented beginning with the contextual module describing the internal and external factors in Yemen, followed by the SIR module, and finally, the humanitarian relief model.

Figure 1 represents the complex web of dynamic factors in the Yemen context, as described in Tables 1-5. Each of the external factors creates second-order effects, which have key consequences related to preparedness and response to cholera outbreaks. The consequences contribute to the growing needs of an affected population. The variables lack of basic commodities (food/medicine/WASH/fuel) and lack of basic services (health/ education/financial) both refer to the basic needs approach standards (Save the Children, 2016) regarding the lack of access to, and availability of, goods and services of substantial quality across multiple sectors. The deprivation of basic goods and services have a direct impact on WASH-related needs, which are the most important factors for preventing and controlling cholera outbreaks (GTFCC, 2017).

Relief efforts seek to lessen the magnitude of the consequences through humanitarian interventions with in-kind assistance and CVA. The primary interactions of providing inkind assistance are denoted on the left-hand side of the model, while CVA is represented on the right-hand side. Local market functionality affects cash/voucher distribution, which influences the purchasing power and can reduce the reliance on remittances and other informal financial networks. By contrast, in-kind distribution is influenced by the identification of material needs in targeted populations and requires physical extant physical infrastructure. In Yemen, both forms of relief efforts are utilized and are not mutually exclusive, contributing to the overall impact on the population receiving assistance. One key distinguishing factor between the two methods of delivering assistance is the delay associated with in-kind distribution. The delays are a result of the poor state of infrastructure in Yemen and reduce the efficiency of in-kind assistance.

In Figure 1, the context is depicted to show the needs, the humanitarian response, and the factors which influence those variables. To understand how the humanitarian response impacts cholera, an intermediary module is needed to describe the response in relation to the population. Figure 2 further examines the relationship between the needs of the population and efforts from humanitarian organizations to provide relief.

Figures 1 and 2 are connected by six variables: four to represent the needs, (reliance on imports, lack of basic services (health/education/financial), lack of basic commodities (food/ medicine/WASH/fuel) and reliance on informal networks) and two to represent the modes of relief (efforts to provide in-kind assistance and efforts to provide cash/voucher assistance). In Figure 2, there are two dynamic feedback loops that describe how humanitarian organizations respond during a complex emergency. The module is adapted from the work of Gonçalves (2011), with two distinctions. First, we show CVA and in-kind assistance through two separate balancing loops, as they are influenced by different variables in Figure 1. Second, we use SDGs in the model as targets for providing relief, which are 


\section{JHLSCM}

11,2

\section{2}

Figure 1.

Compounding factors in the Yemen context

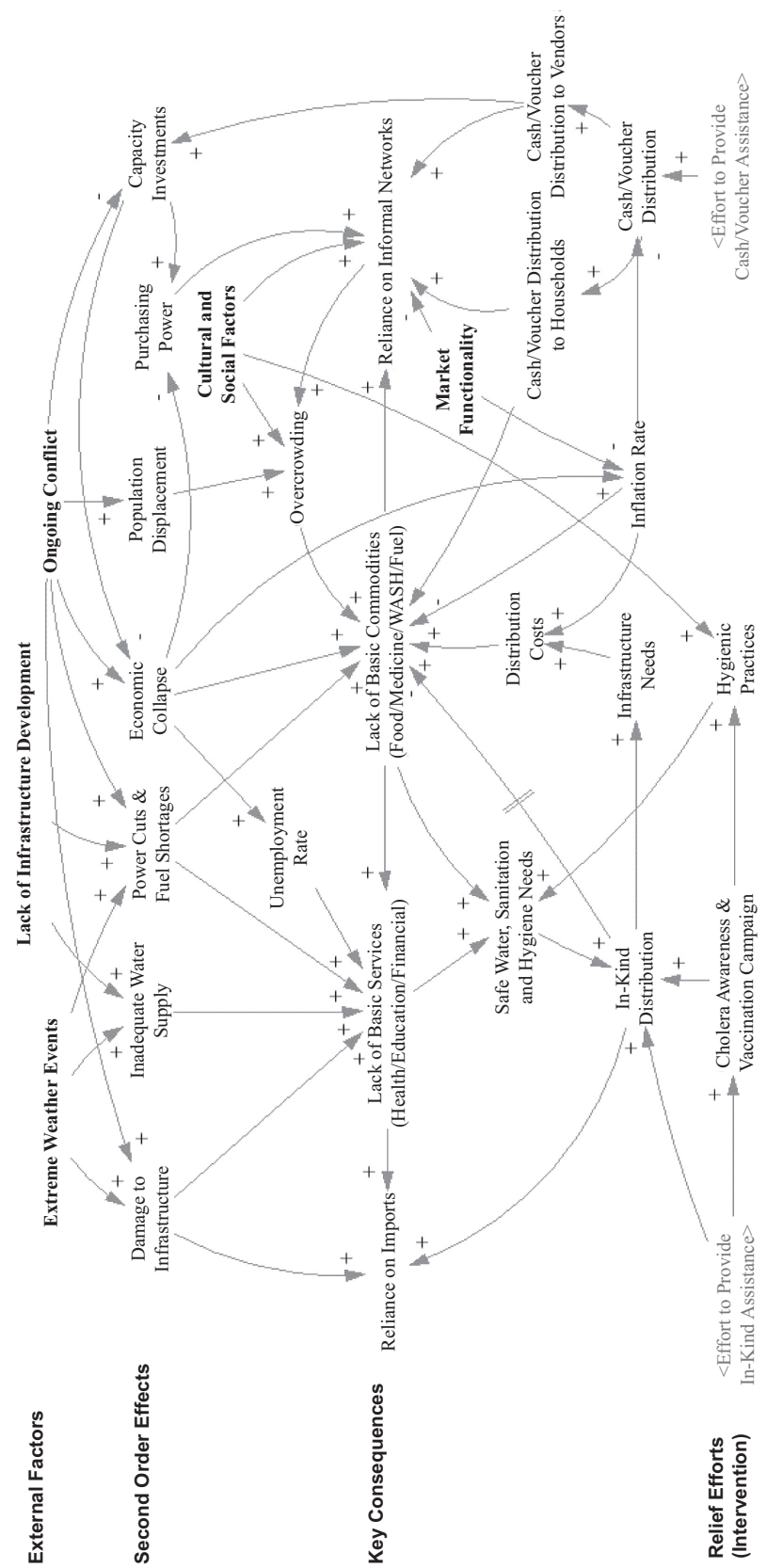




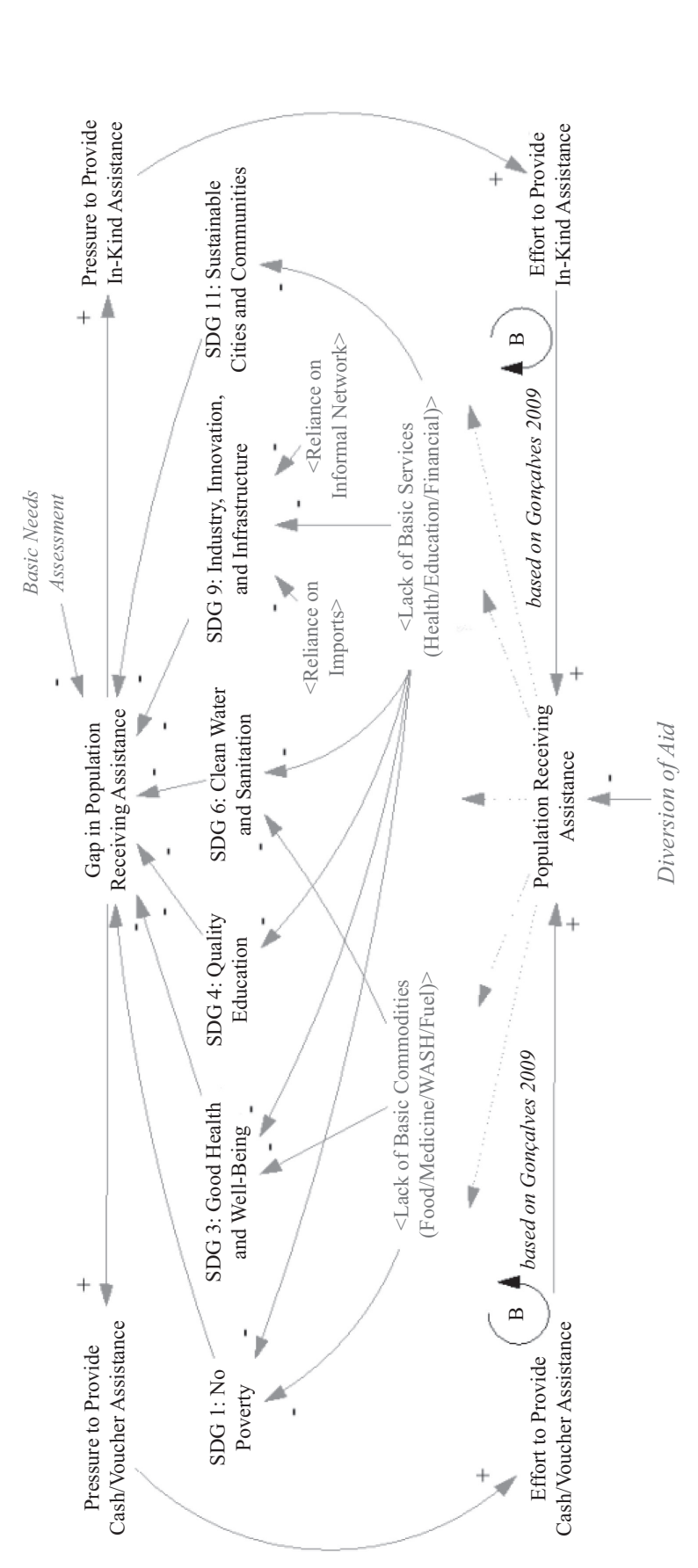

Compounding factors of epidemics

213

Figure 2. Humanitarian efforts and relief loops, adapted from Gonçalves (2011) 
JHLSCM 11,2

connected to the key consequence variables from Figure 1 . These variables are the result of the deteriorating situation in Yemen and have a negative impact on the progress toward the achievement of the six SDGs.

In humanitarian settings, providing the appropriate response requires understanding of the needs of local population. The basic needs assessment is a multi-sectoral approach to quantify the needs of a population and inform humanitarian organizations how to provide an effective response (Save the Children, 2016). The concept of the basic needs is defined as "essential goods, utilities, services or resources required on a regular, seasonal, or exceptional basis by households for ensuring survival and minimum living standards, without resorting to negative coping mechanisms or compromising their health, dignity and essential livelihood assets" (ILO, 1976). We divided basic needs into basic services and basic goods. The assessment explores barriers to a population meeting their basic needs, in terms of access, availability and quality of goods and services. Accurately identifying and specifying the gap in needs can lead to a better formulated humanitarian response plan.

Humanitarian organizations measure their performance on the difference between the identified population who need assistance (gap in population receiving assistance) and the number in a population who receive assistance (population receiving assistance), with a desired target level of performance. If a gap in performance exits, it requires managerial attention to correct poor performance observed in the field. More resources may be allocated to mitigate the compounding risks revealed in, for instance, the basic needs assessment. Depending on the context and environmental situation, humanitarian organizations may decide to provide in-kind assistance, CVA or a combination thereof. Humanitarian organizations are consistently under pressure to provide relief in one of the modalities (pressure to provide in-kind assistance and/or pressure to provide cash/voucher assistance), as resources (money, supplies, people and logistics) and time are often limited. This leads to an increasing effort (effort to provide cash/voucher/in-kind assistance) immediately by allocating more resources toward relief capacities, which positively impacts the population receiving assistance. The model includes the variable diversion of aid, with a negative impact on population receiving assistance, noting that the delivery of aid in conflict zones carries an increased risk of delay or failure, due to confiscation by warring factions, imposition of illegal tariffs, existence of black markets or negative coping mechanisms among beneficiaries (Lischer, 2003).

The six SDG variables refer to specific targets directly and indirectly related to impacts on cholera reduction. The link between the SDG targets and indicators and the problem context are further discussed in Section 4, with specific references to the situation in Yemen. At this stage, the model shows both short- and long-term effects of a population receiving assistance. In the short term, there is a reduction in the gap in population receiving assistance, and in the long term, there is a positive impact toward the achievement of specific SDGs. Responding to cholera outbreaks is multi-dimensional, requiring immediate action for treatment and control and long-term development to prevent future outbreaks (Connolly et al., 2006). Therefore, the model includes both impacts as they work toward a common goal of reducing the risk of cholera infections, as shown in Figure 3.

Figure 3 is connected to Figure 2 through the variable gap in population receiving assistance. This module has been adapted from the widely used SIR model for disease transmission throughout a population (Anderson and May, 1991). A susceptible population is at risk to infection through exposure to the disease. Once infected, individuals may either recover or die. If recovered, individuals may be temporarily immune to cholera, before their susceptibility to the disease is renewed (Koelle et al., 2005).

Connecting the SIR module (Figure 3) to humanitarian assistance in a complex emergency (Figure 2) advances two established models in literature and expands upon them by the inclusion of contextual factors (Figure 1). When an outbreak occurs amidst a population with 


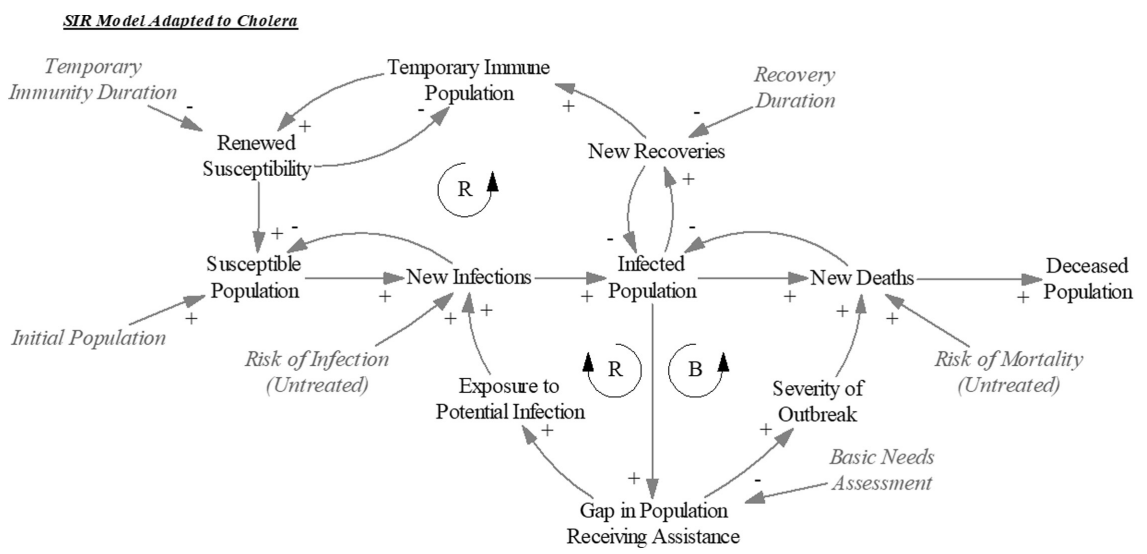

Compounding factors of epidemics

unmet needs, there is a greater risk of exposure to the disease, contributing to the total infected population. The infected population must be treated rapidly to control the spread of the disease, thus contributing to the population requiring assistance and creating a reinforcing loop. Simultaneously, a gap in a population receiving assistance may exacerbate the severity of the outbreak (Dasaklis et al., 2012) and increase the mortality rate.

The inclusion of the context and relief efforts attempts to provide a whole-system perspective, which is often lacking in SIR only models (Homer and Hirsch, 2006). Connecting the three modules together, the model addresses how cholera spreads throughout a population, how humanitarian aid is used to prevent and control outbreaks and internal and external factors that form the boundaries of the system.

The following section provides a discussion of key factors and relationships included in the model, the process validating the model and limitations to the model.

\section{Discussion}

From the structure and causal relationships present in the model, insights can be drawn toward the connection between supply chain functionality and response to disease outbreaks in complex emergencies. In particular, the model reveals a holistic approach toward cholerarelief operations, rather than several piecemeal approaches. The inclusion of both CVA and in-kind assistance provides the perspective of flexible delivery options to provide relief during a cholera outbreak, while the inclusion of SDGs provides a long-term perspective for the prevention of future cholera outbreaks.

\subsection{Sustainable development for cholera prevention in Yemen}

SDGs are an ambitious set of goals that seek to improve the quality of life across the globe. While the 17 SDGs are broadly defined, the UN has also pushed for localization of the goals, so they may be adapted to fit the needs of local and regional communities (UNDP, 2016). Each of the SDGs contains several specific targets that form a roadmap toward achievement of the goals. This research supports this concept by utilizing the SDG targets and indicators as goals for the prevention of future outbreaks of cholera in Yemen.

The model reveals causal relationships in the Yemen context, revealing how supply disruptions occur due to external factors. These factors create needs, represented by the key consequence variables in Figure 1 and in Figure 2, which connect to the SDGs. In Table 6, the four key consequence variables are listed along with specific references to the context in Yemen and the individual SDG indicators that they address. 


\section{JHLSCM \\ 11,2}

216

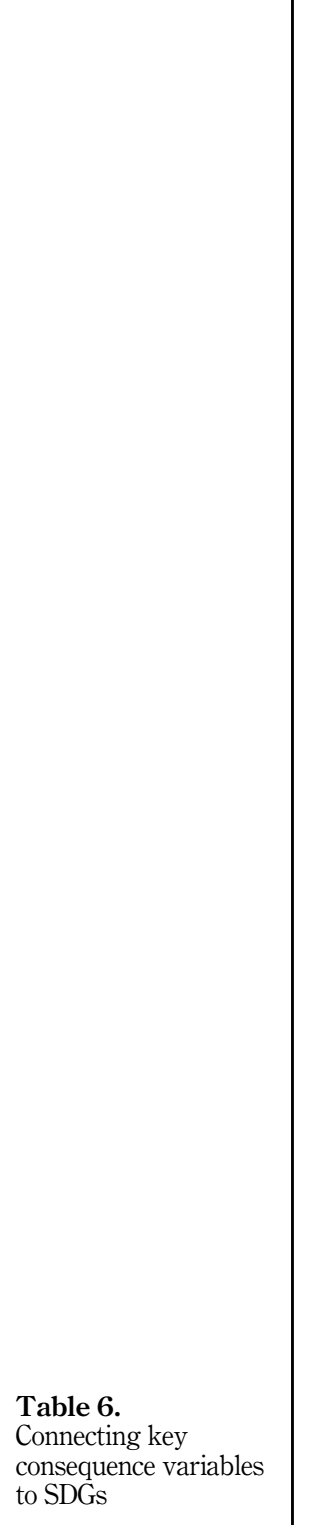

|

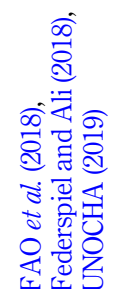

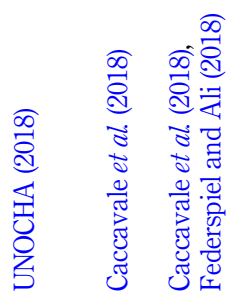

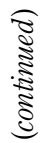

華

पे

离苛

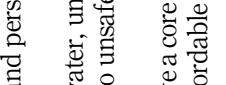

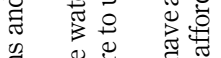

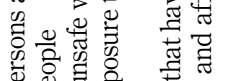

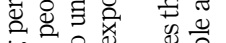

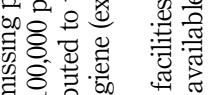

궁

ही

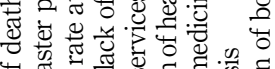

प.

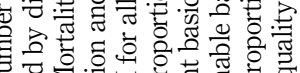

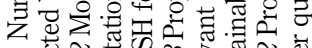

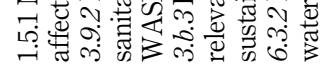

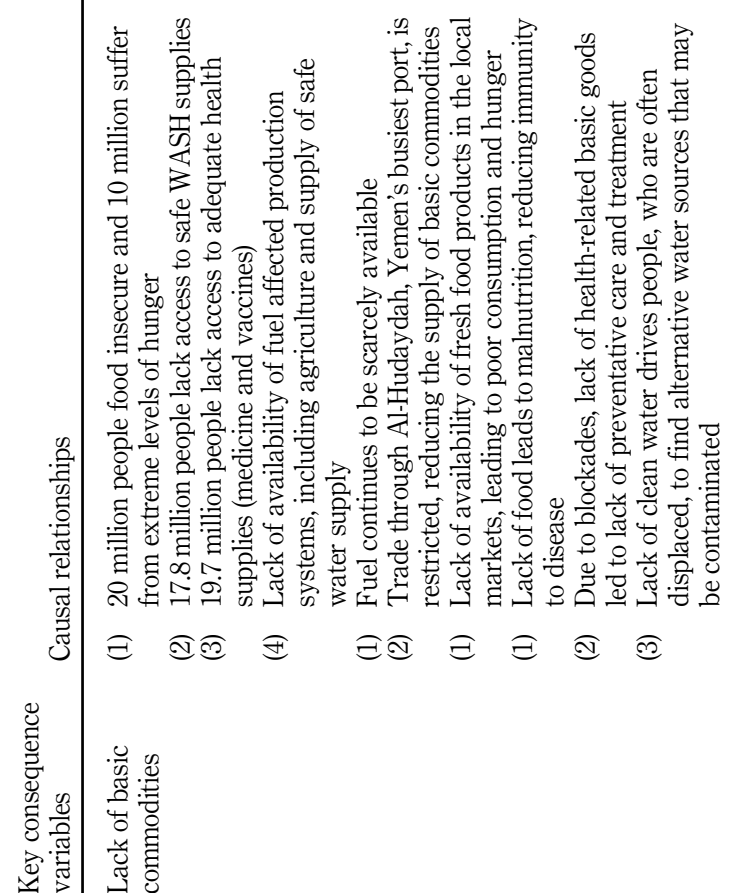




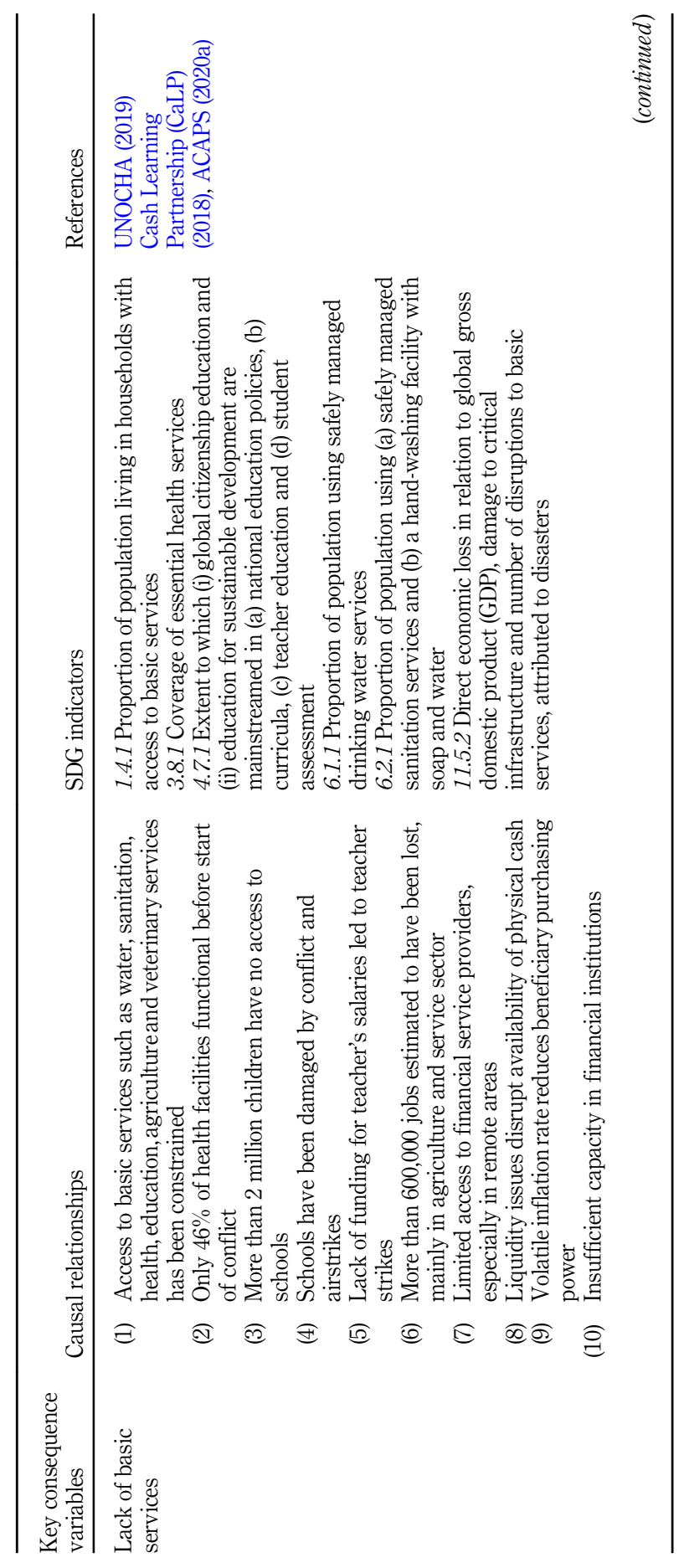

Compounding factors of epidemics

217

Table 6. 


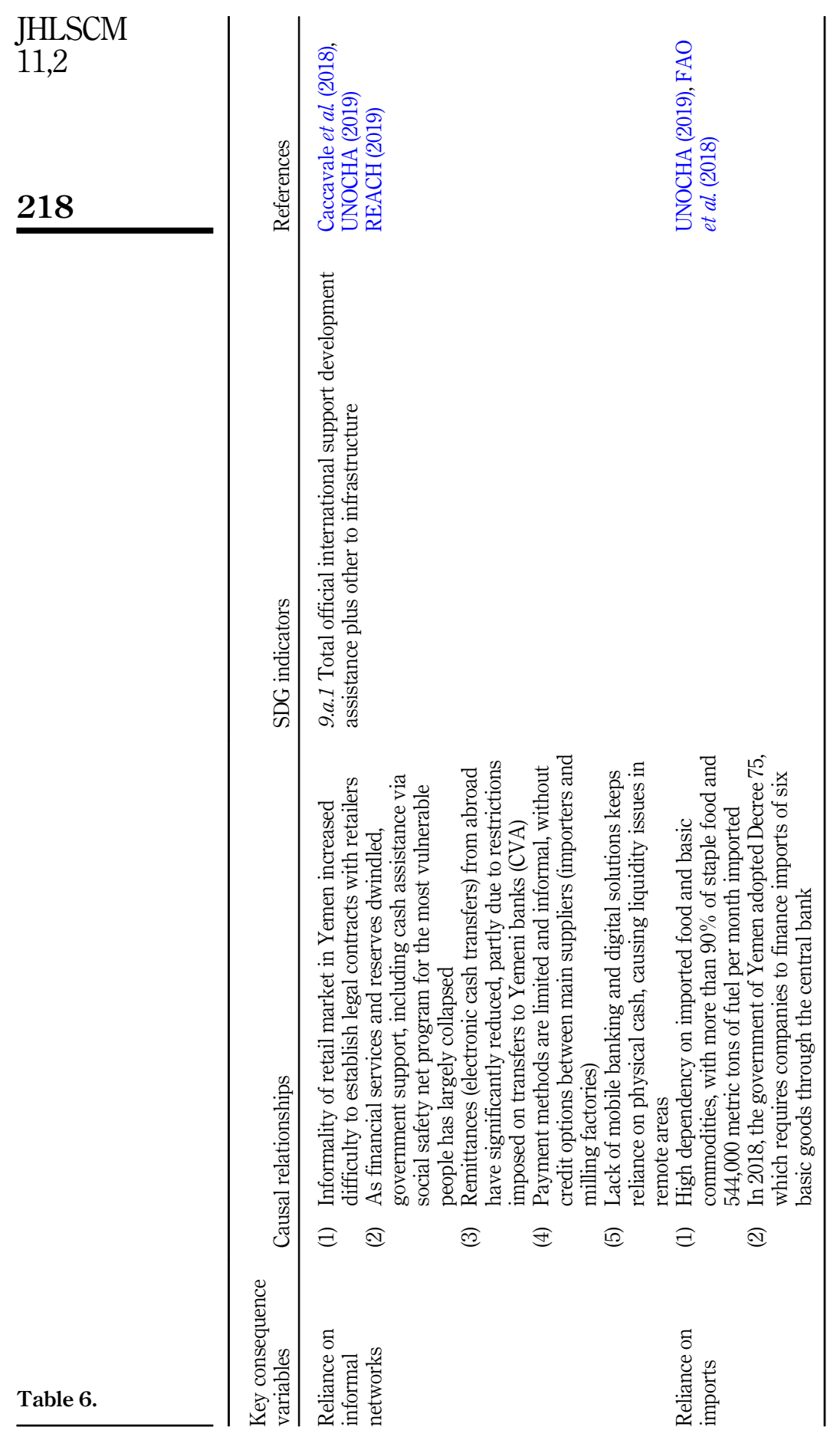


In the model, two clusters of vulnerabilities emerged, needs and dependencies. The lack of basic commodities (food/medicine/wash/fuel) and lack of basic services (health/education/ financial) both refer to the lack of access to, and availability of, goods and services of substantial quality. Protracted crises, such as the one in Yemen, creates acute and chronic needs, both of which must be addressed for the restoration of livelihoods. Scarcity of food, medicine, fuel and WASH products has forced mass displacement and is a driver of insecurity. At the same time, the lack of basic services reflects the deteriorating infrastructure, severely limiting recovery and development options in the country. Addressing these needs has an impact on SDG 1 (no poverty), SDG 3 (good health and well-being), SDG 4 (quality education), SDG 6 (clean water and sanitation) and SDG 11 (sustainable cities and communities). WASH supplies are not the only means necessary to prevent cholera, but also stronger education systems and functioning health services that are available to those who need it.

The resulting lack of commodities and services also highlights two dependencies for providing assistance in Yemen, reliance on informal networks and reliance on imports, in this case. These variables represent underlying features of the Yemen context, forming parameters to how responses can be effectively delivered. Unlike the needs listed above, the dependencies relate primarily to one SDG indicator, 9.a.1, which calls for total international support to improve infrastructure and support development. Reducing the risk of infection of cholera means responding to any current outbreaks and working to prevent future outbreaks through preparedness measures.

Humanitarian interventions typically have short-term, specific goals, while development projects are generally long term with broadly defined goals. However, both share the same common goal of preventing further crisis and reducing the need for humanitarian assistance in the future. In this light, framing humanitarian assistance toward the attainment of specific SDG targets works in the direction of sustainable solutions and links preparedness and development goals together. As CVA is one of the primary mechanisms to deliver assistance in Yemen, there is a strong potential to link relief aid to development goals, which is one of the primary recommendations given by the Overseas Development Institute to improve the effectiveness of humanitarian aid (ODI, 2015).

The continued development of infrastructure can increase the number of options available to humanitarian agencies responding to emergencies. HSC vulnerabilities are a direct result of insufficient infrastructure; thus, it is in the best interest of humanitarian agencies for the persons of concern in emergencies to continue investing in reliable and sustainable transportation, energy and technology. Conflict, extreme weather events and economic crises will continue to create complex emergencies, but by continually developing, maintaining, and protecting basic infrastructure from damage, there is an opportunity to strengthen protection of vulnerable populations against preventable diseases, such as cholera.

\subsection{Model validation}

As the process of building a model is iterative by continuously revisiting several steps to improve the model behavior and structure, so is the process of validating an SD model to determine its adequacy to represent real-world systems (Sterman, 2000). Several qualitative and quantitative methods exist for validation, and serve different purposes depending on the model structure. As the model used in this research did not contain quantitative data, the primary purpose of validation was to gain confidence in the model boundaries, assess the structure of the model and to discuss the relation to real-world counterparts. To accomplish this, semi-structured interviews were chosen as the primary method of validation, which allows respondents to ask questions, elaborate on discussion points and provide insights about causal relationships that might not be available through secondary data (Andersen et al., 2012). 
JHLSCM 11,2

A series of interviews and correspondence took place with an independent WASH consultant who has led the coordination of a working group for the GTFCC. The interviewee is an expert in the problem context, specializing in humanitarian response to cholera outbreaks. Furthermore, interviewee worked directly with the cholera outbreak during the conflict in Yemen. The pattern of validation followed iterations of model analysis and revisions, driven by discussion regarding model parameters, variables, assumptions and limitations with respect to the real-world context. When feedback was received for the model, revisions were made, then discussed again with the key interviewee until a satisfactory level was achieved.

\subsection{Model limitations}

As stated by Grad et al. (2012), modeling of complex problems is limited by the assumptions made and boundaries formed to create the model. One of the goals of this project was to depict the complexity of the situation in Yemen and how humanitarian efforts must consider a myriad of potential scenarios for preparedness and response. The CLD in this research was formulated around logistics and supply chain-related constraints that impact cholera prevention, treatment and control through humanitarian interventions. Thus, several variables were not included in the model, such as socioeconomic factors which influence market functionality.

Additionally, the model does not contain any quantitative values, as the focus of this work was to provide a clear and easy-to-understand representation of the compounding factors. A quantitative analysis of this magnitude would have several factors to compute simultaneously; thus, reliability would be highly difficult to achieve. As noted by Coyle (2000), quantitative modeling of dynamic systems with high degrees of uncertainty may yield misleading results. This model aimed to provide value to practitioners through its depiction of complex relationships between system variables. Despite this, quantification could provide additional value if assumptions and model boundaries are clearly stated. Several SIR cholera models contain a stock and flow diagram, which would be a useful component for an adaptation to this model. In CLD only models, behavior is only inferred, but the inclusion of stock and flow diagrams can increase precision of relationships through detailed variable behavior (Lane, 2008). This additional step is encouraged for future research.

\section{Conclusion}

Communicable diseases are a major cause of mortality during complex emergencies (Connolly, 2005). Cholera is especially prevalent in conflict settings, despite being a preventable disease with international efforts to eradicate it. This research has taken a systems perspective to depict complex factors in a manner that can improve understanding of relationships where numerous uncertainties exist. By utilizing SD and developing CLDs, it was possible to identify and visualize key internal and external factors that either aggravate or mitigate the risk of cholera, which was a key aim of this study.

The CLD developed in this research extends two previous models and presents key factors in a way that allows practitioners and policymakers to have a systematic view of the numerous factors that have complex cause and effect relationships, highlighting potential unintended consequences. When designing assistance programs in a complex emergency, it is important to look at both the short- and long-term needs and dependencies of a population during a cholera outbreak. The findings indicate that there is a need to link both humanitarian and development efforts together with peace mediations to terminate the conflict, or to reduce its intensity. Some factors are possible to address in the short term (i.e. humanitarian assistance and conflict mediation), while others such as education or infrastructural investments need a long-term development approach. Nevertheless, both measures should be taken if humanitarian efforts are to be sustained. 
There is also a need to protect supply chain infrastructure from purposeful attacks and damage, due to the importance for civilian populations. The review of causal relationships in the model affirms the strong coupling between humanitarian response capacity and the level of infrastructure development in Yemen. The country's infrastructure was underdeveloped prior to the conflict, but the lack of maintenance and deterioration due to the conflict further restricted the flow of goods and reduced the number of services available. The inadequate supply chain infrastructure, including ports, roads, water networks and electrical grids, was

determined to be a key factor contributing to the increased risk of cholera outbreaks. While the literature demonstrated that resilience in HSCs is also linked to the level of infrastructure (Papadopoulos et al., 2017), the developed CLD in this study illustrates how humanitarian organizations are able to provide assistance against these settings. Using both in-kind assistance and CVA simultaneously provides flexibility to counter supply chain and market disruptions. Additionally, assistance must be multi-dimensional, taking immediate action for cholera treatment and control and sustaining long-term development to prevent future outbreaks. Thus, formulating context-specific solutions is encouraged, which may potentially improve resiliency toward disruptions through multiple forms of assistance.

Connecting the model to SDGs highlights which targets and indicators are most important to address in the complex emergencies. Maintenance and protection of existing infrastructure and further development at the country level are beyond most of humanitarian assistance operations, as they require large-scale investments. Using the SDGs provides a roadmap for how to develop infrastructure where it is most needed. Visual representation of variable interrelationships is easier to understand than text; thus, the model could be used as a tool for educational purposes and program preparation to align humanitarian and development initiatives. However, development of infrastructure alone is not enough, as there is a simultaneous need for multi-dimensional improvements, such as education related to hygiene. Therefore, to counter the effects of external factors, flexible assistance and alignment of objectives across sectors is needed to mitigate the risk of cholera outbreaks.

In addition, while there are differences between cholera and COVID-19, caused by the airborne SARS-CoV-2 virus, some of the factors, such as the need for logistics and health-care infrastructure, are relevant in both cases. Moreover, if a vaccine against the SARS-CoV-2 virus will require temperature-controlled transportation, then relevant infrastructure for distribution will be necessary to complete vaccination programs. While this model is built around the cholera epidemic, it can be adapted to assess responses for other infectious diseases.

The results of the research should be taken forward, which may include testing the model in different settings (e.g. country, region or type of disease) as well as incorporating quantification through stock and flow diagrams on well-defined small-scale problem instances. There is also the possibility for action research, applying the model during an intervention and assessing the impacts of the various responses. Further work might also include surveys to collect views of practitioners on the importance of each factor and the relationships between them, which may uncover additional factors that influence how responses are formulated.

\section{References}

ACAPS (2019), "Humanitarian access overview, October 2019", available at: https://www.acaps.org/ sites/acaps/files/products/files/20191031_acaps_humanitarian_access_overview_october_2019. pdf (accessed 26 May 2020). 
JHLSCM 11,2

ACAPS (2020a), "Volatility of the Yemeni Riyal: drivers and impact", available at: https://www.acaps. org/sites/acaps/files/products/files/20200129_acaps_yemen_analysis_hub_drivers_and_ impact_of_yer_volatility_0.pdf (accessed 28 April 2020).

ACAPS (2020b), "Yemen analysis hub: risk overview March 2020", available at: https://www.acaps. org/sites/acaps/files/products/files/20200402_acaps_yemen_analysis_hub_risk_overview_ april_2020.pdf (accessed 28 April 2020).

Andersen, D.L., Luna-Reyes, L.F., Diker, V.G., Black, L., Rich, E. and Andersen, D.F. (2012), "The disconfirmatory interview as a strategy for the assessment of system dynamics models", System Dynamics Review, Vol. 28 No. 3, pp. 255-275.

Anderson, R.M. and May, R.M. (1991), Infectious Diseases of Humans: Dynamics and Control, Oxford University Press, New York.

Anjomshoae, A., Hassan, A., Kunz, N., Wong, K.Y. and de Leeuw, S. (2017), "Toward a dynamic balanced scorecard model for humanitarian relief organizations' performance management", Journal of Humanitarian Logistics and Supply Chain Management, Vol. 7 No. 2, pp. 1-24.

Armendáriz, V., Armenia, S. and Atzori, A.S. (2016), "Systemic analysis of food supply and distribution systems in city-region systems - an examination of FAO's policy guidelines towards sustainable agri-food systems", Agriculture, Vol. 6 No. 4. No. 65, pp. 1-19.

Berariu, R., Fikar, C., Gronalt, M. and Hirsch, P. (2015), "Understanding the impact of cascade effects of natural disasters on disaster relief operations", International Journal of Disaster Risk Reduction, Vol. 12, pp. 350-356.

Berariu, R., Fikar, C., Gronalt, M. and Hirsch, P. (2016), "Training decision-makers in flood response with system dynamics", Disaster Prevention and Management, Vol. 25 No. 2, pp. 118-136.

Besiou, M., Stapleton, O. and Van Wassenhove, L.N. (2011), "System dynamics for humanitarian operations", Journal of Humanitarian Logistics and Supply Chain Management, Vol. 1 No. 1, pp. 78-103.

Burkle, F.M. (1999), "Lessons learnt and future expectations of complex emergencies”, BMJ, Vol. 319 No. 7207 , pp. $422-426$.

Caccavale, O., Flaming, T. and Hachandi, C. (2018), Food Markets in the Time of Conflict and Cholera: Rapid Market Assessment in Yemen, WFP, Rome.

Cash Learning Partnership (CaLP) (2018), "CTP in challenging contexts: case study on CTP and risks in Yemen 2015-2018", available at: http:/www.cashlearning.org/downloads/user-submittedresources/2018/10/1540822102.CaLP\%20Yemen\%20CTP\%20Case\%20Study.pdf (accessed 26 May 2020).

Chaignat, C.L. and Monti, V. (2007), "Use of oral cholera vaccine in complex emergencies: what next? Summary report of an expert meeting and recommendations of WHO", Journal of Health, Population, and Nutrition, Vol. 25 No. 2, pp. 244-261.

Chao, D.L., Longini, I.M. and Morris, J.G. (2014), "Modeling cholera outbreaks", Current Topics in Microbiology and Immunology, Vol. 359, pp. 195-209.

Codeço, C. (2001), "Endemic and epidemic dynamics of cholera: the role of the aquatic reservoir", BMC Infectious Diseases, Vol. 1 No. 1, pp. 1-14.

Colwell, R.R. (1996), “Global climate and infectious disease: the cholera paradigm”, Science, Vol. 274 No. 5295, pp. 2025-2031.

Conceição, P. (2019), Human Development Report 2019, United Nations Development Programme, available at: $\mathrm{http}: / \mathrm{hdr}$.undp.org/en/2019-report.

Connolly, M.A., Gayer, M., Ryan, M.J., Salama, P., Spiegel, P. and Heymann, D.L. (2004), "Communicable diseases in complex emergencies: impact and challenges", The Lancet, Vol. 364 No. 9449, pp. 1974-1983. 
Connolly, M.A. (Ed.) (2005), Communicable Disease Control in Emergencies: A Field Manual, World Health Organization.

Coyle, G. (2000), "Qualitative and quantitative modelling in system dynamics: some research questions", System Dynamics Review: The Journal of the System Dynamics Society, Vol. 16 No. 3, pp. 225-244.

Dasaklis, T.K., Pappis, C.P. and Rachaniotis, N.P. (2012), "Epidemics control and logistics operations: a review”, International Journal of Production Economics, Vol. 139 No. 2, pp. 393-410.

Devereux, S. (2006), Cash Transfers and Social Protection, Paper prepared for the Regional Workshop on Cash Transfer Activities in Southern Africa, Johannesburg.

Diniz, V.B., Borges, M.R., Gomes, J.O. and Canos, J.H. (2005), "Knowledge management support for collaborative emergency response", The 9th International Conference on Computer Supported Cooperative Work in Design Proceedings, Coventry, UK, pp. 1188-1193.

ECHO (2013), The Use of Cash and Vouchers in Humanitarian Crises, DG ECHO funding guidelines, European Civil Protection and Humanitarian Aid Operations (ECHO), Brussels, Belgium.

Elluru, S., Gupta, H., Kaur, H. and Singh, S.P. (2019), "Proactive and reactive models for disaster resilient supply chain”, Annals of Operations Research, Vol. 283 Nos 1-2, pp. 199-224.

FAO, IFAD, UNICEF, W.F.P. and WHO (2018), The State of Food Security and Nutrition in the World 2018. Building Climate Resilience for Food Security and Nutrition, FAO, Rome.

Federspiel, F. and Ali, M. (2018), "The cholera outbreak in Yemen: lessons learned and way forward", BMC Public Health, Vol. 18 No. 1338, pp. 1-8.

Fink, M.D. (2017), "Naval blockade and the humanitarian crisis in Yemen", Netherlands International Law Review, Vol. 64 No. 2, pp. 291-307.

Fuss, M. (2016), "Increasing health care access in Yemen through community-based health insurance", Indiana Journal of Global Legal Studies, Vol. 23 No. 2, pp. 795-818.

Gayer, M., Legros, D., Formenty, P. and Connolly, M.A. (2007), "Conflict and emerging infectious diseases", Emerging Infectious Diseases, Vol. 13 No. 11, pp. 1625-1631.

Global Task Force on Cholera Control (2017), Ending Cholera. A Global Roadmap to 2030, WHO, Geneva.

Gonçalves, P. (2011), "Balancing provision of relief and recovery with capacity building in humanitarian operations", Operations Management Research, Vol. 4 Nos 1-2, pp. 39-50.

Grad, Y.H., Miller, J.C. and Lipsitch, M. (2012), "Cholera modeling: challenges to quantitative analysis and predicting the impact of interventions", Epidemiology, Vol. 23 No. 4, pp. 523-530.

Hammer, C.C., Brainard, J. and Hunter, P.R. (2018), "Risk factors and risk factor cascades for communicable disease outbreaks in complex humanitarian emergencies: a qualitative systematic review", BMJ Global Health, Vol. 3 No. 4, pp. 1-10.

Heaslip, G., Sharif, A.M. and Althonayan, A. (2012), "Employing a systems-based perspective to the identification of inter-relationships within humanitarian logistics", International Journal of Production Economics, Vol. 139 No. 2, pp. 377-392.

Heaslip, G., Kovács, G. and Haavisto, I. (2018), "Cash-based response in relief: the impact for humanitarian logistics", Journal of Humanitarian Logistics and Supply Chain Management, Vol. 8 No. 1, pp. 87-105.

Homer, J.B. and Hirsch, G.B. (2006), "System dynamics modeling for public health: background and opportunities", American journal of public health, Vol. 96 No. 3, pp. 452-458.

ILO (1976), International Labour Office, "Employment Growth and Basic Needs: A One-World Problem. Report of the Director-General of the International Labour Office”, ILO, Geneva.

Inter-Agency Standing Committee (IASC) (1994), Orientation Handbook on Complex Emergencies, OCHA, Geneva.
Compounding factors of epidemics 
JHLSCM 11,2

Ivanov, D., Sokolov, B. and Dolgui, A. (2014), "The ripple effect in supply chains: trade-off 'efficiencyflexibility-resilience' in disruption management", International Journal of Production Research, Vol. 52 No. 7, pp. 2154-2172.

Jüttner, U. and Maklan, S. (2011), "Supply chain resilience in the global financial crisis: an empirical study", Supply Chain Management, Vol. 16 No. 4, pp. 246-259.

Kapucu, N. and Garayev, V. (2011), "Collaborative decision-making in emergency and disaster management”, International Journal of Public Administration, Vol. 34 No. 6, pp. 366-375.

Kelly-Hope, L.A. (2008), "Conflict and emerging infectious diseases", Emerging Infectious Diseases, Vol. 14 No. 6, pp. 1004-1005.

Koelle, K., Rodó, X., Pascual, M., Yunus, M. and Mostafa, G. (2005), "Refractory periods and climate forcing in cholera dynamics", Nature, Vol. 436 No. 7051, pp. 696-700.

Kovács, G. and Tatham, P. (2009), "Responding to disruptions in the supply network - from dormant to action", Journal of Business Logistics, Vol. 30 No. 2, pp. 215-229, doi: 10.1002/j.2158-1592.2009. tb00121.x.

Lane, D.C. (2008), “The emergence and use of diagramming in system dynamics: a critical account", Systems Research and Behavioral Science: The Official Journal of the International Federation for Systems Research, Vol. 25 No. 1, pp. 3-23.

Lischer, S.K. (2003), "Collateral damage: humanitarian assistance as a cause of conflict", International Security, Vol. 28 No. 1, pp. 79-109.

Logistics Cluster (2010), "Logistics capacity assessment: Yemen”, available at: https://reliefweb.int/ sites/reliefweb.int/files/resources/AC729BEC4EFEC5C8852577690063F10E-Full_Report.pdf (accessed 20 July 2020).

Macias, L. (2013), “Complex emergencies research brief”, Climate Change and African Political Stability Briefs, The University of Texas at Austin, Austin, No. 16.

Martin-Simpson, S., Parkinson, J. and Katsou, E. (2018), "Measuring the benefits of using market based approaches to provide water and sanitation in humanitarian contexts", Journal of Environmental Management, Vol. 216, pp. 263-269.

Medici, A.M. (Ed.) (2014), After the Yemeni Spring: A Survey on the Transition, Mimesis International.

Morecraft, J. (2007), Strategic Modelling and Business Dynamics: A Feedback Systems Approach, John Wiley \& Sons, West Sussex.

Mukandavire, Z. and Morris, J. (2015), "Modeling the epidemiology of cholera to prevent disease transmission in developing countries", Microbiology Spectrum, Vol. 3 No. 3, pp. 1-10.

ODI (2015), Overseas Development Institute, "Doing cash differently: how cash transfers can transform humanitarian aid", available at: https://www.odi.org/sites/odi.org.uk/files/odi-assets/ publications-opinion-files/9828.pdf (accessed 26 May 2020).

Papadopoulos, T., Gunasekaran, A., Dubey, R., Altay, N., Childe, S.J. and Fosso-Wamba, S. (2017), "The role of Big Data in explaining disaster resilience in supply chains for sustainability", Journal of Cleaner Production, Vol. 142, pp. 1108-1118.

Peck, H. (2006), "Reconciling supply chain vulnerability, risk and supply chain management", International Journal of Logistics: Research and Applications, Vol. 9 No. 2, pp. 127-142.

Perelson, A.S. (2002), "Modelling viral and immune system dynamics", Nature Reviews Immunology, Vol. 2 No. 1, pp. 28-36.

Piotrowicz, W.D. (2018), "In-kind donations, cash transfers and local procurement in the logistics of caring for internally displaced persons", Journal of Humanitarian Logistics and Supply Chain Management, Vol. 8 No. 3, pp. 374-397.

Pruyt, E. and Hamarat, C. (2010), "The influenza A (H1N1) v pandemic: an exploratory system dynamics approach", Proceedings of the 28th International Conference of the System Dynamics Society, Seoul, Korea, July 2010, System Dynamics Society, pp. 25-29. 
Puri, J., Aladysheva, A., Iversen, V., Ghorpade, Y. and Brück, T. (2017), "Can rigorous impact evaluations improve humanitarian assistance?", Journal of Development Effectiveness, Vol. 9 No. 4, pp. 519-542.

Rachah, A. and Torres, D.F. (2015), "Mathematical modelling, simulation, and optimal control of the 2014 Ebola outbreak in West Africa", Discrete Dynamics in Nature and Society, Vol. 2015, pp. 1-9.

REACH Initiative (2017), "Market functionality and community perception of cash based assistance", available at: https://reliefweb.int/sites/reliefweb.int/files/resources/reach_yem_report_joint_ cash_study_dec2017.pdf (accessed 26 May 2020).

REACH Initiative (2019), "Secondary desk review of cash and markets data for Yemen", available at: https://www.impact-repository.org/document/reach/aae534a8/REACH_YEM_SDR_Cash-andMarkets-data_November-2019.pdf (accessed 26 May 2020).

Sabates-Wheeler, R. and Devereux, S. (2010), "Cash transfers and high food prices: explaining outcomes on Ethiopia's Productive Safety Net Programme”, Food Policy, Vol. 35 No. 4, pp. 274-285.

Save the Children (2016), "Basic needs assessment guidance and toolbox", available at https:/www. calpnetwork.org/wp-content/uploads/2020/03/basic-needs-assessment-backgroundconcepts-1. pdf (accessed 20 July 2020).

Sterman, J.D. (2000), Business Dynamics: Systems Thinking and Modeling for a Complex World, McGraw-Hill, New York, NY.

UNDP (2016), "Roadmap for localizing the SDGs: implementation and monitoring at subnational level", available at: https://sustainabledevelopment.un.org/content/documents/commitments/818_11195_ commitment_ROADMAP\%20LOCALIZING\%20SDGS.pdf (accessed 18 November 2020).

UNHCR (2020), “2019 Year-end report. Operation: Yemen”, available at: https://reporting.unhcr.org/ sites/default/files/pdfsummaries/GR2019-Yemen-eng.pdf (accessed 19 November 2020).

UNOCHA (2018), “2018 Yemen humanitarian response plan”, available at: https:/reliefweb.int/report/ yemen/yemen-humanitarian-response-plan-januarydecember-2018-enar (accessed 26 May 2020).

UNOCHA (2019), "Yemen: 2019 humanitarian needs overview”, available at: https://reliefweb.int/sites/ reliefweb.int/files/resources/2019_Yemen_HNO_FINAL.pdf (accessed 20 July 2020).

Wolstenholme, E.F. (1999), "Qualitative vs quantitative modelling: the evolving balance", Journal of the Operational Research Society, Vol. 50 No. 4, pp. 422-428.

World Bank (2020a), "Yemen monthly economic update: April 2020", available at: http://pubdocs. worldbank.org/en/609141590055031061/Yemen-Monthly-Economic-Update-April-2020-eng.pdf (accessed 28 May 2020).

World Bank (2020b), "Population, total, Yemen", available at: https://data.worldbank.org/indicator/SP. POP.TOTL?locations $=$ YE (accessed 2010 2020).

World Health Organization (2004), Cholera Outbreak: Assessing the Outbreak Response and Improving Preparedness, WHO, Geneva.

World Health Organization (2009), "Prevention and control of cholera outbreaks: WHO policy and recommendations. WHO position paper on prevention and control of cholera outbreak", available at: http://www.who.int/cholera/technical/prevention/control/en/index.html.

World Health Organization (2010), "Acute diarrhoeal diseases in complex emergencies: critical steps. Decision making for preparedness and response", available at: https://www.who.int/cholera/ publications/criticalsteps/en/ (accessed 26 May 2020).

World Health Organization (2017), "Yemen cholera situation report No. 4", available at: http://www. emro.who.int/yem/yemeninfocus/situation-reports.htm (accessed 4 May 2020).

World Health Organization (2020), "Cholera situation update in Yemen - January 2020", available at: https:/applications.emro.who.int/docs/EMCSR252E.pdf?ua=1andua=1 (accessed 06 June 2020). 
JHLSCM

11,2

226
Wu, J.T., Leung, K., Bushman, M., Kishore, N., Niehus, R., de Salazar, P.M., Cowling, B.J., Lipsitch, M. and Leung, G.M. (2020), "Estimating clinical severity of COVID-19 from the transmission dynamics in Wuhan, China”, Nature Medicine, Vol. 26 No. 4, pp. 506-510.

\section{Corresponding author}

Russell Harpring can be contacted at: russell.harpring@hanken.fi

For instructions on how to order reprints of this article, please visit our website: www.emeraldgrouppublishing.com/licensing/reprints.htm Or contact us for further details: permissions@emeraldinsight.com 